\title{
Explanation of tuberculation scales formation in steel and iron pipes using the theory of wave motion of a liquid
}

\author{
Alexey Andrianov* and Evgeny Orlov \\ Moscow State University of Civil Engineering (National Research University), Department of Water \\ Supply and Sewerage, 129337 Yaroslavskoe shosse 26, Moscow, Russia
}

\begin{abstract}
Electrochemical corrosion of steel and iron pipes in water supply systems is a common problem that causes financial losses to operating companies and deteriorates water quality. A comprehensive study of corrosion deposits formation mechanism is necessary for a better understanding of the processes occurring in pipelines and for scientific justification of monitoring and predicting techniques. The influence of various factors (in particular the water flow velocity) on the formation, growth, and spatial distribution of tuberculation scales on the inner surface of pipes is considered. To study the effect of flow velocity, simple serial tests were carried out on segments of a steel non-galvanized pipe in static and dynamic conditions. The difference in the formation of anode and cathode sections in two dynamic modes is recognized. The first stage of tubercle formation is observed. It was assumed that in pipes with turbulent water flow near metal surface, waves forming tubercles are appeared, and the distribution of the tubercles is depend on water flow velocity.
\end{abstract}

\section{Introduction}

Steel and cast iron pipes are widely used in external and internal water supply systems. Therefore, operators stay focused on the problem of metal pipe corrosion, since it leads to financial losses and degradation of tap water quality. In order to provide scientifically grounded methods for control and forecasting of internal corrosion processes in the pipes, a comprehensive study of the corrosion deposits formation mechanism is required.

Literature devoted to corrosion of steel and cast iron pipes in water supply systems [1-7] provides a shared understanding of the morphology and composition of corrosion deposits, which normally have the form of tubercles and are identified by the characteristic structural elements such as a thin surface layer and a dense shell covering a loose core [7,8]. However, there is almost no information about tubercles formation and growth. The most complete description of processes occurring during corrosion in steel and cast iron pipes is given in [7]. Briefly, the basic statements of the proposed model are as follows. Growth of a tubercle results from corrosion, which is accompanied by precipitation and oxidation of corrosion products. As the sediment thickness grows, the oxidant's ability to diffuse to the

\footnotetext{
*Corresponding author: alexei-waterlab@yandex.ru
} 
metal/water interface becomes increasingly impaired. Various structural elements of corrosion sediments begin to form during this intermediate stage. A dense (shell-like) layer develops in a position determined by the depth of oxidant penetration into the sediment. As tubercles grow, they cover an increasingly large area and eventually may merge with other tubercles, thus covering the entire inner surface of a pipe and preventing the penetration of oxidant to the metal surface of the pipe [7]. In case of continuous corrosion, tubercles grow from within the sediment. Successive fractures in the dense layer may lead to formation of several shell-like layers. The fractures can be caused by variations of water temperature, as well as by expansion of corrosion products in the tubercle core.

The proposed model lacks a description of a concrete mechanism for generation of tubercles and the dense layer. Most likely, it is related to the fact that the review of the corrosion process totally excludes the properties of water itself. Water is regarded as an element of the corrosion environment rather than an active factor [9].

In our previous paper [10], we made an assumption about the impact of water motion on tubercle formation. In this case, their active growth starts when oxygen concentrations under the base sediment drops below $1 \mathrm{mg} / \mathrm{l}$ and the dense layer is generated by cathodic reduction of the loose $\gamma$-FeOOH sediment to magnetite $\mathrm{Fe}_{3} \mathrm{O}_{4}$ [11]. The lepidocrocite-tomagnetite reduction ensures permanent thickness of the dense layer during tubercle growth.

In our opinion, the corrosion processes under tubercles occur in anaerobic conditions and involve hydrogen depolarization, hydrogen gas release, as well as increase of iron hydroxide concentration in the thin water layer adjacent to the metal. Hydrogen gas bubbles generate pressure on the core-forming layers, resulting in their deformation, lifting and tubercle growth. When iron hydroxide solution, which fills the cavity after a bubble is removed, becomes supersaturated, the cavity undergoes mass crystallization resulting in formation of a spherulitic skin consisting mainly of goethite and lepidocrocite. This sediment forms a laminated base for a tubercle. Bubble movement within the sediment is directed towards the pipe center, and is induced by the difference in water pressure in the center and near the pipe walls, which occurs only in the presence of liquid motion.

Described above are two models of tubercle formation. However, despite numerous works, there is no explanation for tubercle genesis and their spatial distribution over the inner surface of a pipe. Localization of corrosion nodules is commonly explained by metal properties and inhomogeneous structure, which is resulted in generation of electrochemical corrosion elements. Examination of deposits appearance in water pipes showed a certain pattern of tubercle distribution over the pipe surface, similar to water or sand waves, which triggered the present study. In this paper, we would like to propose a tubercle growth model beginning from their initiation stage. The hypothesis is based on the assumption that growth and formation of the tubercle base was considerably influenced by water velocity in pipes.

\section{Materials and methods}

The majority of works dedicated to corrosion study test coupons or samples of pipes removed from an operating water supply system. The disadvantage of such works is that there is no opportunity to perform a long-term visual observation of the corrosion process. In order to determine the localization of tubercles and the corrosion rate on the inner pipe surface, two samples were cut out from a new water pipe made of unlined steel St37.0. The sample diameters were $25 \mathrm{~mm}$, the wall thicknesses were $2.8 \mathrm{~mm}$.

The study was conducted in three corrosion modes: one under static conditions, and two under dynamic conditions. In the static mode, the sample was kept submerged in a tank containing stagnant tap water for different periods of time (test series 1.x). In the dynamic mode, a water jet was falling from the height of $45 \mathrm{~cm}$ into a tank containing the sample. In a first case, the jet was falling at sample side (series 2.x), and in a second case, it was 
falling over the sample center (series 3.x). During the experiment, the modes were successively altered with multiple test repetitions.

The water quality in the period of the experiment: $\mathrm{pH}=7.9-8.1, \mathrm{t}=14-16^{\circ} \mathrm{C}$, alkalinity - $2.5 \mathrm{mEq} / \mathrm{L}$, hardness - $135 \mathrm{mg}-\mathrm{CaCO}_{3} / \mathrm{L}, \mathrm{Ca}^{2+}-37 \mathrm{mq} / \mathrm{l}$, TDS $-210 \mathrm{mg} / \mathrm{L}$, dissolved oxygen in static mode $-6-6.5 \mathrm{mg} / \mathrm{L}$, dissolved oxygen in dynamic mode $-11-12 \mathrm{mg} / \mathrm{L}$. Langelier stability index was $0.1 \ldots-0.7$, i.e., the water was mildly aggressive.

Area of sample No.1 $\mathrm{S}_{1}=60 \mathrm{~cm}^{2}$, area of sample No.2 $\mathrm{S}_{2}=64 \mathrm{~cm}^{2}$. Iron density D = $7.874 \mathrm{~g} / \mathrm{cm}^{3}$. Formula for calculation of the corrosion rate per unit area $\left(\mathrm{g} / \mathrm{m}^{2} \cdot \mathrm{h}\right)$ :

$$
K_{s}=M \cdot 10^{4} /(S \cdot T),
$$

Where: $M=M_{1}-M_{2}$ is sample mass lost in a test (mass of steel removed due to corrosion), $\mathrm{g} ; M_{1}, M_{2}$ is sample mass at the beginning and at the end of a test respectively, $\mathrm{g} ; S$ is sample area $\left(\mathrm{cm}^{2}\right) ; T$ is exposure time, $\mathrm{h}$.

The mineral composition and morphology of the sediment was assessed using SEM and EDX analysis performed with a Quanta 250 FEI. Dissolved oxygen in water was determined with a WTW Oxi 3310 oxygen meter.

\section{Results and discussion}

\subsection{Evaluation of water motion impact on the corrosion rate}

The images of the control samples are shown in Figure 1. The data of corrosion rate shown in Figure 2 demonstrate reduction of the corrosion rate both in sample No.1 and sample No.2. It should be noted that change of the hydraulic mode results in a short-term increase of the corrosion rate in sample No.1 (tests 1.0, 2.0, 3.0, 3.3, 2.5, 1.2) which then decreases again to reach the average values. The corrosion rate decline was especially strong in test 3.4. Visual inspection of the sample showed that tubercles formed on the surface at spots located away from the falling jet. Thus, the corrosion rate decline can be regarded as an interaction of two simultaneous processes: corrosion and sedimentation.

The experiment results demonstrated that in case of stagnant water loose iron hydroxide sediment is formed throughout the tank volume. The sediment can be easily washed off from the sample surface with a water jet. Anodic and cathodic sites are evenly distributed over the entire surface of the sample, while their sizes do not exceed 1-2 $\mathrm{mm}^{2}$. The corrosion rate of the sample No.1 was decreased from 0.149 to $0.078 \mathrm{~g} / \mathrm{m}^{2} \cdot \mathrm{h}$ in the first 14 days, what can be explained by a decline in the rate of oxygen diffusion to the sample surface through the sediment layer. The corrosion rate for the second sample in the stagnant water test (Figure 2, test 1.5) dropped from 0.133 to $0.034 \mathrm{~g} / \mathrm{m}^{2} \cdot \mathrm{h}$ in 30 days. Simultaneously, $\mathrm{pH}$ increased from 8.10 to 8.52 and alkalinity decreased from 2.5 to 1.8 $\mathrm{mEq} / \mathrm{L}$, which indicate that a sediment containing siderite $\left(\mathrm{FeCO}_{3}\right)$ is formed on the metal surface.

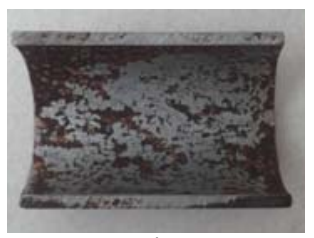

a)

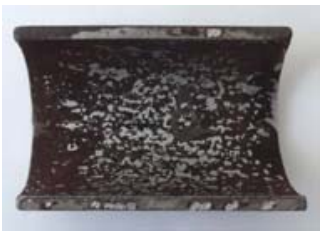

b)

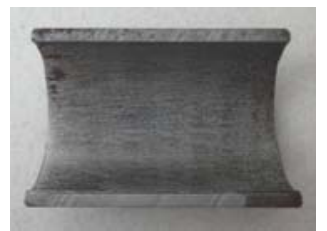

c)

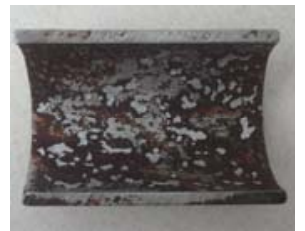

d)

Fig. 1. External appearance of samples: a) sample No.1, test 3.2, total exposure time 24 days; b) sample No.2, test 1.1, exposure time 4 days; c) sample No.2, test 1.3, exposure time 14 days;

d) sample No.1, test 2.4 , exposure time 42 days. 

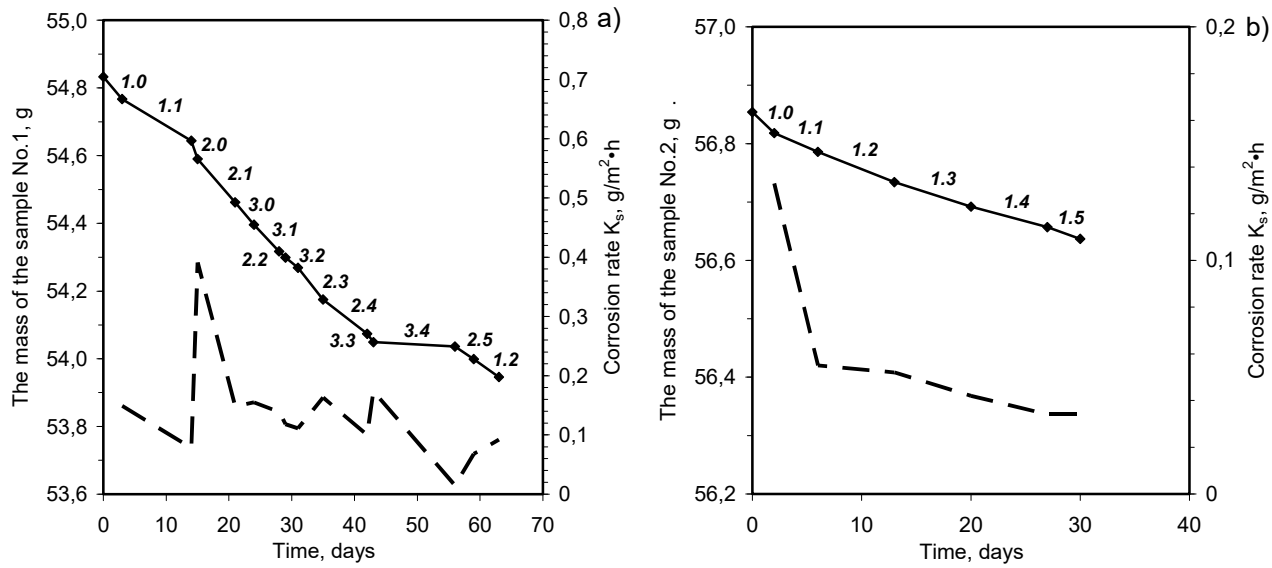

Fig. 2. Results of sample No.1 (a) and No.2 (b) mass (-) and corrosion rate (- - -) determination.
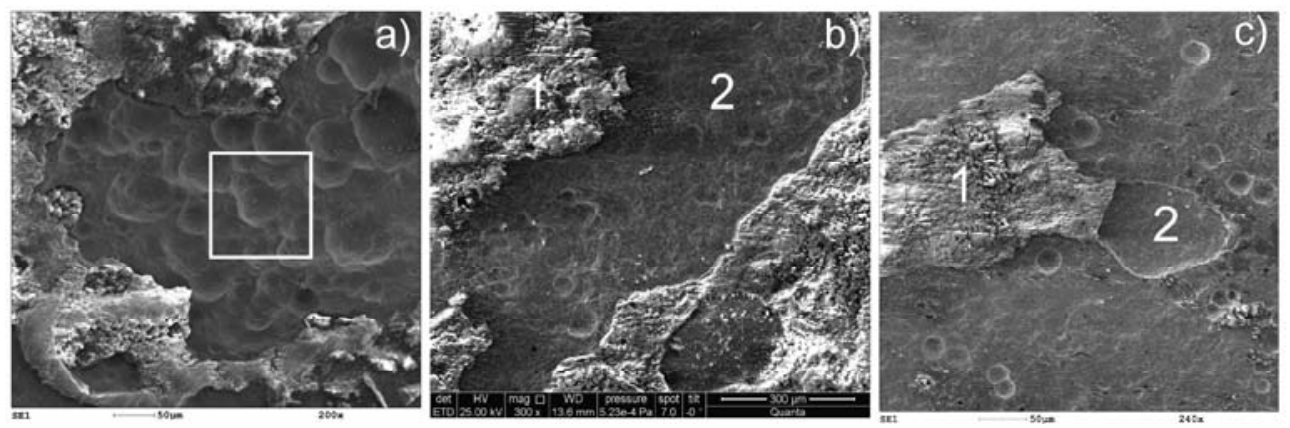

Fig. 3. Microphotographs of sediments and the surface of the sample No. 1: a) test 2.4; b), c) test 3.1; 1 - anodic sites, 2 - cathodic sites.

In the mode of side water jet, the sample became covered with sediments in about 24 hours; the sediments had stronger adhesion to the surface and could be removed only mechanically, with a sponge. The areas of single anodic and cathodic sites did not exceed $0.5 \mathrm{~cm}^{2}$, with the total areas being almost equal (Figure 1a). Cathodic sites were free from sediments, anodic sites were covered with iron hydr(oxide) sediments. The corrosion rate was at its maximum of $0.196 \mathrm{~g} / \mathrm{m}^{2} \cdot \mathrm{h}$ after 15 days (when the modes were changed from the first to the second one) and went down to $0.050 \mathrm{~g} / \mathrm{m}^{2} \cdot \mathrm{h}$ after 42 days. The corrosion process involves oxygen and hydrogen depolarization, while the contribution of hydrogen depolarization is significant. Figure 1d and Figure 3a show the appearance of the sample surface corresponding to the test conditions in mode 2 . When a water jet was supplied into the tank over the sample center, no loose sediments were observed over the entire exposure period. The corrosion rate was $0.070-0.059 \mathrm{~g} / \mathrm{m}^{2} \cdot \mathrm{h}$. The corrosion process involves oxygen depolarization. Figure $3 \mathrm{~b}$ and $3 \mathrm{c}$ show images corresponding to the test conditions in mode 3 . It can be concluded from Figure 2 that, with the change of the hydraulic mode, the corrosion rate grew more than twofold compared to the previous mode. This occurred due to dissolution of the base sediment. Therefore, it can be concluded that the change in the hydrodynamic conditions led to expansion of the areas of cathodic and anodic sites relative to the static condition, and also led to a significant increase in the corrosion rate. The second sample was kept exposed to stagnant water for 36 days. During this time, the corrosion rate fell from 0.133 to $0.034 \mathrm{~g} / \mathrm{m}^{2} \cdot \mathrm{h}$. Since there was no change in the hydraulic mode, the corrosion rate did not increase after the sample had been removed for intermediate measurements of weight loss (Figure 2). 


\subsection{Analysis of the structure and composition of corrosion sediments on metal surface}

Table 1 provides the chemical composition corresponding to cathodic and anodic sites for different exposure times as identified by EDX. It is primarily iron on the cathode (at sites most readily accessible by oxygen), while the sediment on the anode has a complex composition and can be interpreted as a mix of siderite $\left(\mathrm{FeCO}_{3}\right)$ and a small amount of hydroxides of aluminum, calcium and zinc (test 3.1). The impact of $\mathrm{FeCO}_{3}$ on formation of a protective film on the pipe surface was noted in [6], since this compound precipitates much earlier that calcium carbonate. Thus, the most probable event would be formation of siderite having crystalline compatibility with iron, at the anodic sites. The composition of sediment at anodic sites shows that siderite content in the sediment declines and iron oxide content increases as sample exposure time grows. This promotes generation of a dense layer over the anode with formation of magnetite during cathodic reduction of iron hydroxides. However, the content of iron oxides declined again while the content of oxides of aluminum, silicon, zinc and calcium carbonate in the sediment increased after 56 days, which is more characteristic for the surface layer of a tubercle. Thus, two out of the three structural elements of a tubercle were formed during the experiment time. However, tubercle core formation requires a longer time.

Table 1. Chemical composition of sediments in various areas of an electrochemical corrosion element.

\begin{tabular}{|l|l|c|c|c|c|c|c|c|c|}
\hline \multicolumn{1}{|c|}{ Sample } & Sample & \multicolumn{9}{|c|}{ Atomic percent At, \% } \\
\cline { 3 - 11 } & site & $\mathrm{C}$ & $\mathrm{O}$ & $\mathrm{Fe}$ & $\mathrm{Al}$ & $\mathrm{Si}$ & $\mathrm{K}$ & $\mathrm{Ca}$ & $\mathrm{Zn}$ \\
\hline Sample No. 1, & Cathodic & - & - & 100.0 & - & - & - & - & - \\
\cline { 2 - 11 } $\mathrm{T}=$ 28 days, test 3.1 & Anodic & 15.51 & 53.07 & 25.95 & 0.47 & 1.37 & - & 2.28 & 1.35 \\
\hline Sample No. 1, & Cathodic & 6.64 & - & 92.26 & - & 0.55 & 0.13 & - & 0.20 \\
\cline { 2 - 11 } $\mathrm{T}=$ 42 days, test 2.4 & Anodic & 19.89 & 45.71 & 31.97 & - & 1.05 & - & 1.38 & - \\
\hline Sample No. 1, & Cathodic & - & 17.47 & 78.41 & - & - & - & - & 4.12 \\
\cline { 2 - 10 } $\mathrm{T}=$ 56 days, test 3.4 & Anodic & 11.49 & 51.11 & 24.88 & 0.88 & 1.49 & - & 7.96 & 2.19 \\
\hline Sample No. 2, & Cathodic & - & 8.33 & 91.67 & - & - & - & - & - \\
\cline { 2 - 10 } $\mathrm{T}=$ 27 days, test 1.4 & Anodic & 18.42 & 36.22 & 45.36 & - & - & - & - & - \\
\hline
\end{tabular}

\subsection{Hydrodynamic model of tubercle formation}

During water motion in a pipe, the friction force generates waves at the metal/water interface. These waves cause migration of water particles both in the vertical and in the horizontal planes along the flow direction. Travelling of particles away from the pipe surface is induced by the excess of lift power over the particle weight in water. A jet falling on the water surface in dynamic tests imitates water hammer resulting in generation of waves spreading in the tank in all directions. In case of a side fall of the jet, turbulent pulsations have low energy and cannot remove all corrosion products from the sample surface. Therefore, the sample becomes covered with loose sediment after some time. With a jet falling over the sample center, corrosion progresses without formation of loose sediment and with no visible enlargement of the tuberculation. In this mode cathodic sites are localized at spots of the highest stream energy and a continuous access of oxygen to the metal surface. Anodic sites are formed at the periphery where the stream impact is lower. These areas are subject to sediment precipitation and, correspondingly, their resistance to oxygen diffusion grows even higher. Formation of a dense layer begins over the anode, with the layer gradually covering its surface. The anodic sites of metal degradation constantly move, leaving caverns on metal surface (Figure 3a). Migration of anodic and cathodic sites, i.e., their transpassivation, ends when the dense layer is finally fixed on the metal surface by electrostatic forces. In this case, the whole surface of the dense layer 
begins to act as a cathode. It is the particular moment when initiation and further growth of tubercles becomes possible. In the present experiment, formation of tubercles on sample No. 1 began after 56 days. It can be suggested that tubercle-forming waves are generated during turbulent water motion in pipes at the water/metal interface. Simultaneously, the vertical element of the wave, i.e., its amplitude peak with the maximum energy, ensures maximum oxygen supply to the metal surface, thus determining the location for cathodic site formation. Anodic sites are generated in locations where the wave energy is insufficient to break the sediment off the surface. Therefore, the next wave determines the location for the next tubercle. Since water velocity in a constant diameter pipe changes depending on the flow rate, tubercles are relatively homogeneously distributed over the inner surface of the pipe. This suggests that inter-tubercle distances will grow as water velocity and pipe diameter increase.

\section{Conclusions}

The conducted studies have shown that water motion causes formation of larger cathodic and anodic sites in samples of unlined steel pipes, which sites turn into tubercles during further corrosion. Water velocity is a factor, which determines spatial distribution and growth of tubercles on the inner surface of a pipe. So, the formation of tubercles in pipes is a specific instance of wave actions in the nature. A substantial condition for tubercle growth is strong adhesion of their bases to the pipe metal. Hence, it can be concluded that the variable operation of a water supply network during the day at maximum and minimum flow velocities promotes a formation of protective layer in stable and mildly aggressive water and prolongs the service life of steel pipes. It should be noted that the deposits obtained in our experiments are still far from those that are formed in the pipes after longterm operation. For a more detailed study of tubercle deposit formation it is necessary to carry out more prolonged experiments in continuous flow regime.

\section{References}

1. R. A. Pisigan, J. E. Singley, J. AWWA 77(11), 76-82 (1985)

2. Y. Zhang, M. Edwards, J. of Water Supply: Res. \& Tech. - AQUA 56 (1), 55-68 (2007)

3. P. Sarin, V. L. Snoeyink, J. Bebee, W. M. Kriven, J. A. Clement, Water Res. 35 (12), 2961-2969 (2001)

4. T. L. Gerke, J. B. Maynard, M. R. Schock, D. L. Lytle, Corrosion Sci. 50 (7), 20302039 (2008)

5. C. Y. Peng, G. V. Korshin, R. L. Valentine, A. S. Hill, M. J. Friedman, S. H. Reiber, Water Res. 44 (15), 4570-4580 (2010)

6. P. Sarin, V. L. Snoeyink, J. Bebee, K. K. Jim, M. A. Beckett, W. M. Kriven, J. A. Clement, Water Res. 38 (5), 1259-1269 (2004)

7. P. Sarin, V. L. Snoeyink, D. A. Lytle, W. M. Kriven, J. of Environmental Engineering 130 (4), 365-373 (2004)

8. R.I. Ray, J.S. Lee, B.J. Little, T.L. Gerke, Materials and Corr. 61 (12), 993-999 (2010)

9. F. Yang, B. Shi, J. Gu, D. Wang, M. Yang, Water Res. 46 (16), 5423-5433 (2012)

10. A. P. Andrianov, V. A. Chuhin, Water and ecology 3, 18-34 (2016)

11. B. McEnaney, D.C. Smith, Corrosion Sci. 20, 873-886 (1980) 